\title{
A Gardnerella vaginalis e as infecções do trato urinário
}

\section{The Gardnerella vaginalis and the urinary tract infections}

Alessandro Conrado de Oliveira Silveira'; Helena Aguilar Peres Homem de Mello de Souza²; Carlos Augusto Albini ${ }^{3}$

unitermos
Gardnerella vaginalis
Infecções do trato urinário
Bactérias fastidiosas

Bactérias fastidiosas

\section{resumo}

As infecções do trato urinário (ITUs) estão entre as mais frequentes nos seres humanos. São causadas por grande variedade de uropatógenos habituais, porém podem ser provocadas por alguns micro-organismos fastidiosos, como a Gardnerella vaginalis, que é uma bactéria anaeróbia facultativa, observada sob a forma de cocobacilos Gram-variáveis. Ela habita a mucosa vaginal e eventualmente pode ocasionar ITUs. O isolamento pode ser realizado em amostras de urina utilizando o ágar CNA (colistina e ácido nalidíxico), com incubação de 48 a 72 horas em atmosfera rica em $\mathrm{CO}_{2}$. O exame de Gram de urina não centrifugada pode auxiliar o microbiologista na identificação das amostras nas quais uma bactéria fastidiosa seja o agente causal, já que a visualização de inúmeras células epiteliais, a ausência de leucócitos e a presença de mais de um tipo morfológico sugerem contaminação da amostra. Como estudos comprovam a incidência de $G$. vaginalis entre os agentes causadores de ITUs, o isolamento em uroculturas não deve ser desprezado. A interpretação clínica do crescimento da G. vaginalis é de difícil avaliação, sendo imprescindível a troca de informações entre o laboratório de microbiologia clínica e a equipe médica, investigando a presença de sinais e sintomas que possam estar associados à ITU.

\section{abstract}

Urinary tract infections are among the most recurrent in human beings. They are caused by a wide variety of usual uropathogens, although they may be caused by some fastidious micro-organisms, such as Gardnerella vaginalis. It is a facultative anaerobe, found in the form of Gram-variable coccobacilli. It inhabits the vaginal mucosa and occasionally may cause urinary tract infections. The isolation may be performed on urine samples using CNA agar, incubated for 48-72 hours in atmosphere rich in $\mathrm{CO}_{2}$. The Gram examination of non-centrifuged urine may aid the microbiologist in identifying samples in which a fastidious bacterium is the causative agent, since the visualization of numerous epithelial cells, the absence of leukocytes and the presence of more than one morphological type suggest sample contamination. As studies show the Gardnerella vaginalis incidence among the causative agents of urinary tract infections, the isolation in urine cultures can not be overlooked. The clinical interpretation of the Gardnerella vaginalis growth is difficult to assess, thus being essential the information exchange between the clinical microbiology laboratory and medical staff in order to investigate the presence of signs and symptoms that may be associated with urinary tract infections. key words

Gardnerella vaginalis

Urinary tract infections

Fastidious bacteria

1. Mestre em Ciências Farmacêuticas; professor de Microbiologia Clínica do Departamento de Ciências Farmacêuticas da Fundação Universidade Regional de Blumenau (FURB).

2. Mestra em Microbiologia, Parasitologia e Patologia; bioquímica do Hospital de Clínicas da Universidade Federal do Paraná (HC-UFPR).

3. Mestre em Educação; professor do departamento de Patologia Médica da UFPR. 


\section{Introdução}

Considerando-se as infecções humanas, as das vias urinárias estão entre as mais comuns, ocupando o segundo lugar depois das infecções respiratórias ${ }^{(5)}$. Resultam em aproximadamente oito milhões de consultas médicas por ano e cerca de um milhão de admissões em hospitais. A frequência exata das infecções do trato urinário (ITUs) não é conhecida, entretanto, de acordo com evidências atuais de consultórios médicos e prontuários hospitalares, é estimada em sete milhões de casos de cistite e 250 mil de pielonefrite por ano nos EUA ${ }^{(14)}$.

Como resultado da grande frequência de infecções urinárias e da facilidade de obtenção de amostras, as culturas de urina representam a maior parte do contingente de exames em laboratórios de microbiologia clínica ${ }^{(4)}$.

As ITUs são ocasionadas por grande variedade de patógenos. Os agentes causais habitualmente isolados são os bacilos Gram-negativos (BGNs), especialmente Escherichia coli, Proteus mirabilis e Klebsiella pneumoniae. Entre os cocos Gram-positivos destacam-se Enterococcus faecalis, Streptococcus agalactiae e Staphylococcus saprophyticus. Tais micro-organismos não requerem condições especiais para o isolamento, como meios enriquecidos, incubação prolongada e/ou atmosfera rica em $\mathrm{CO}_{2}{ }^{(21)}$.

Os métodos tradicionais de cultivo da urina permitem o crescimento da maioria dos uropatógenos, porém algumas bactérias que ocasionalmente causam ITUs necessitam de protocolos distintos para isolamento, dificultando o diagnóstico etiológico. É imprescindível que o laboratório de microbiologia reconheça as limitações dos métodos atuais e, em circunstâncias especiais, possa investigar algumas espécies bacterianas que possam ser responsáveis pelo processo infeccioso. Entre os uropatógenos potenciais, porém infrequentes, podemos destacar Corynebacterium urealyticum, Gardnerella vaginalis, Mycoplasma hominis, entre outros ${ }^{(5)}$

Assim, apesar de ainda estar associada principalmente à vaginose bacteriana, a $G$. vaginalis está sendo isolada com maior frequência em pacientes com sintomatologia característica de ITU, principalmente em mulheres. Em alguns casos, por intermédio de coleta suprapúbica, também foi isolada de pacientes assintomáticos ${ }^{(6,24)}$.

Surpreendentemente, poucos trabalhos foram realizados nos últimos anos relacionando a $G$. vaginalis com as ITUs. Este estudo realizou uma revisão bibliográfica em artigos publicados nos últimos 30 anos sobre essa associação.

\section{Características}

A G. vaginalis, anteriormente denominada Haemophilus vaginalis e Corynebacterium vaginale, é uma bactéria anaeróbia facultativa, imóvel, observada sob a forma de cocobacilos Gram-variáveis. Desde sua primeira descrição por Gardner e Dukes em 1955, é reconhecida por colonizar o trato genital feminino. A doença mais comum que o micro-organismo pode causar é a vaginose bacteriana, mas doenças graves, como bacteriemias e meningites, já foram descritas. Em homens, o achado das bactérias usualmente é considerado irrelevante clinicamente, porém já foram relatados casos de uretrite, prostatite e ITUs(23).

Ela é uma bactéria fastidiosa, que necessita de meios ricos para o isolamento. Pode ser utilizado o ágar Columbia, que contém biotina, ácido fólico, niacina e tiamina, ou ainda o ágar Chocolate, com incubação de 48 horas a $37^{\circ} \mathrm{C}$ e em atmosfera rica em $\mathrm{CO}_{2}$. Suas colônias são pequenas (cerca de $0,5 \mathrm{~mm}$ ), opacas e $\beta$-hemolíticas. Hemolisam o sangue humano, mas não de carneiro. Entre as principais características bioquímicas, destacam-se oxidase $(-)$, catalase $(-)$, hidrólise do hipurato $(+)$, produção de ácido a partir de glicose, inositol (-), manitol (-) e rhamnose $(-)^{(22)}$.

A G. vaginalis coloniza preferencialmente o trato genital feminino. $O$ fato se deve a duas razões: o líquido seminal contém altas concentrações de zinco, que pode inibir a bactéria, e o epitélio prostático contém células colunares, que dificultam a adesão da $G$. vaginalis. Entretanto, estudos mostram taxas de colonização em homens saudáveis que variam de $7,2 \%$ a $11,4 \%$, podendo atingir $38 \%$ dos casos quando cultivada especificamente para o agente ${ }^{(23)}$.

A característica marcante dessa bactéria é apresentar reação ao Gram-variável. O fato ocorre devido à fina camada de peptidoglicano encontrada, constituindo apenas 20\% do peso da parede celular, semelhante aos $23 \%$ encontrados em Escherichia coli e muito menor que a porcentagem observada em estafilococos, estreptococos e lactobacilos. Consequentemente, vários isolados da G. vaginalis podem aparecer como Gram-positivos, Gram-negativos ou Gramvariáveis. Apesar da delgada camada de peptidoglicano, a parede celular das bactérias não contém compostos normalmente encontrados nas bactérias Gram-negativas, como ácidos micólicos e galactanas. A composição química é semelhante à encontrada nas espécies de Corynebacterium, motivo que justifica o fato de a bactéria ser descrita junto às Gram-positivas (27). 


\section{Doenças associadas}

Desde a primeira descrição, muitos estudos foram realizados para avaliar a participação da G. vaginalis na patogênese das doenças genitourinárias e sexualmente transmissíveis. Durante vários anos, os ginecologistas admitiram que a bactéria fazia parte da microbiota vaginal normal. Entretanto, o micro-organismo é a causa de $90 \%$ das infecções vaginais sintomáticas que anteriormente eram descritas como não específicas. A partir do momento que a $G$. vaginalis começou a ser encontrada em culturas de mulheres assintomáticas, alguns autores sugeriram que ela isoladamente não poderia provocar infecção, mas o faria na presença de algumas bactérias anaeróbias, causando desconforto e corrimento vaginal fétido. Observou-se que em alguns casos a bactéria foi isolada juntamente com estafilococos. É encontrada também em associação a outros patógenos vaginais, como Trichomonas vaginalis e algumas espécies de micoplasmas ${ }^{(26)}$.

Em pacientes com balanopostite, a G. vaginalis aparece como segundo agente com maior prevalência, sendo responsável por $31 \%$ dos casos não relacionados com Candida spp. A infecção é caracterizada por abundante secreção fétida e presença de mácula na superfície da mucosa prepucial. Em $75 \%$ dos casos de isolamento da G. vaginalis houve crescimento concomitante de Bacteroides sp., evidenciando a possibilidade da participação das bactérias na patogênese da doença ${ }^{(10)}$.

Podemos encontrar a $G$. vaginalis no esperma em aproximadamente $10,7 \%$ dos homens que mantêm relações sexuais com mulheres sintomáticas. Nesses casos, clue-cells (células-guia) são observadas na coloração de Gram. Tais homens permanecem assintomáticos, porém podem apresentar complicações e transmitir a bactéria em futuras relações sexuais ${ }^{(26)}$.

A prevalência da $G$. vaginalis em mulheres grávidas assintomáticas foi demonstrada por Macdowall et al.(15), por meio de coleta suprapúbica, eliminando a possibilidade de contaminação pelas vias urinárias inferiores. Entre as gestantes, $18 \%$ encontravam-se colonizadas. Em $84 \%$ das mulheres com suspeita e/ou doença renal, a $G$. vaginalis foi isolada ${ }^{(15)}$.

Em homens, a presença da $G$. vaginalis na uretra é assintomática, mas a bactéria pode assumir papel patogênico pela extensão com a próstata e a bexiga, especialmente em pacientes que sofreram alguma manipulação urológica. A presença de colônias em contagens superiores a 10 mil unidades formadoras de colônia por mililitro (UFC/ml) em urina de jato médio é muito difícil de avaliar, pois é encontrada tanto em homens assintomáticos como naqueles com doença renal, obstrução ureteral, cistite pós-cateterismo e prostatite crônica ${ }^{(3,25)}$.

A G. vaginalis pode ser isolada também em pacientes com uretrite, que apresentam secreção e disúria. Em alguns casos, devido à própria sintomatologia do paciente, a presença de clue-cells pode ser confundida com a suspeita de gonorreia. Recomenda-se que seja realizada a cultura para que se possa eliminar o problema. Aproximadamente 10\% dos casos de uretrite não gonocócica são causados pela G. vaginalis(17).

Em estudo realizado por Agarwal e Dixon investigou-se o possível papel da G. vaginalis na cistite intersticial, usando métodos moleculares para garantir a recuperação do microorganismo mesmo em baixas contagens. Nenhuma das 33 amostras de biópsias de bexiga de pacientes com cistite intersticial foi positiva para G. vaginalis, o que, embora não exclua seu envolvimento na cistite intersticial, diminui essa probabilidade ${ }^{(1)}$.

\section{Patogenicidade}

Apesar de reconhecidamente mostrar baixa virulência, a G. vaginalis apresenta alguns fatores de virulência já bem estabelecidos. Além de pili, ela apresenta uma camada de exopolissacarídeo, que justifica o grande poder de adesão dessa bactéria às células epiteliais. Em 1990, Rottini et al. ${ }^{(20)}$ descreveram uma toxina citolítica, capaz de lisar principalmente as hemácias humanas, uma vez que possuem atividade sobre os polimorfonucleares e as células epiteliais, porém costumam fazê-lo em concentrações superiores àquelas que promovem lise nas hemácias humanas ${ }^{(3,20)}$.

As clue-cells são células epiteliais escamosas cuja superfície está repleta de bactérias semelhantes à $G$. vaginalis. São muito comumente encontradas em esfregaços vaginais e também em urinas colhidas por punção suprapúbica em mulheres. Assim, podem ser observadas em homens (no sêmen), secreção uretral e swabs uretrais. A adesão às células epiteliais permite à bactéria colonizar a mucosa vaginal, minimizando o contato com enzimas extracelulares e anticorpos locais, reduzindo as chances de ser eliminada junto com o fluido vaginal ou a urina ${ }^{(3)}$.

A patogenicidade da $G$. vaginalis no trato urinário já foi sugerida por vários pesquisadores. Fairley e Birch demonstraram que a bactéria pode aderir ao epitélio escamoso da bexiga em pacientes com cistite. A primeira descrição do micro-organismo a partir de isolados urinários foi realizada 
por McFadyn e Edkyn em 1968. Foram utilizadas amostras obtidas por punção suprapúbica, sendo que em $15,9 \%$ das mulheres grávidas sadias foi isolado o micro-organismo. Dados semelhantes foram obtidos por McDowall et al. que, em 1981, reportaram G. vaginalis em $18 \%$ das grávidas saudáveis e em $56 \%$ das mulheres grávidas com doenças renais associadas ${ }^{(15,19,21)}$.

Em 1991, Lam e Birch realizaram um estudo sobre a sobrevivência da $G$. vaginalis na urina, relacionando-a com temperatura e $\mathrm{pH}$. No que se refere à temperatura, observaram que após 6 horas da urina mantida a $37^{\circ} \mathrm{C}$ a contagem de colônias diminuiu em mais de $90 \%$; já no que tange ao $\mathrm{pH}$, a faixa ótima para crescimento situa-se entre pH 6 e 7,5. Em pH 6, o declínio da contagem de colônias em 6 horas foi de mais de $50 \%$, sendo que em $\mathrm{pH} 7$ a queda foi cerca de $1 \%$. Os autores também demonstram que a presença de Ureaplasma urealyticum favorecia o desenvolvimento da G. vaginalis, pois promovia a degradação da ureia, alcalinizando o $\mathrm{pH}^{(11,12)}$.

Tais fatos sugerem que a sobrevivência da $G$. vaginalis na urina é um fenômeno complexo: $\mathrm{pH}$ ácido e temperatura de $37^{\circ} \mathrm{C}$ são inibitórios. Assim, recomenda-se que a urina seja semeada em intervalos inferiores a 2 horas e, quando não for possível, armazenada a $4^{\circ} \mathrm{C}$.

\section{Procedimentos laboratoriais}

Apesar de a G. vaginalis crescer em meios utilizados rotineiramente no laboratório, como o ágar Sangue e o Chocolate, por exemplo, o uso de meios seletivos facilita o isolamento da bactéria, visto que, por se tratar de um micro-organismo que requer condições especiais para o crescimento, pode em muitos casos ser descartada pelo laboratório, mesmo estando presente na amostra.

O meio mais indicado para o crescimento da $G$. vaginalis é o ágar CNA, que utiliza como base o ágar Columbia, acrescido de sangue de carneiro e antibióticos. A adição de ácido nalidíxico e colistina inibe o crescimento de enterobactérias e Pseudomonas spp., bem como de leveduras e alguns Gram-positivos ${ }^{(27)}$.

Em amostras obtidas por punção suprapúbica ou de pacientes com suspeita de síndrome uretral aguda, a amostra deve ser semeada com alça calibrada de 0,01 ml (1:100), considerando qualquer crescimento, e deve-se fazer a identificação e o antibiograma ${ }^{(16)}$.

Deve-se realizar a coloração de Gram de urina não centrifugada, homogeneizando bem a urina, pipetando $10 \mu \mathrm{l}$ em lâmina, deixando secar ao ar e depois procedendo com a coloração de Gram. A presença de uma ou mais bactérias por campo geralmente é relacionada com contagens de colônias superiores a $100.000 \mathrm{UFC} / \mathrm{ml}$. A presença de grande número de células epiteliais, a ausência de leucócitos e a presença de mais de um tipo morfológico sugerem contaminação da amostra ${ }^{(16)}$.

Como a G. vaginalis é uma bactéria fastidiosa, pode não crescer nos meios de cultura habituais ou requerer maior tempo de incubação. Somente com o exame de Gram poderemos suspeitar da condição, como também verificar a presença de clue-cells(2). Apresenta crescimento sutil, formando colônias com 0,3 a 0,5 mm de diâmetro, com hemólise difusa, visualizada mais facilmente após incubação prolongada (72 horas). Necessita atmosfera de $5 \%$ a $7 \%$ de $\mathrm{CO}_{2}$ e temperaturas entre 35 e $37^{\circ} \mathrm{C}$. A bactéria usualmente cresce em 24 horas, porém é mais bem visualizada e identificada após 48 a 72 horas de incubação(27).

\section{Discussão}

Ginestre-Pérez et al.(7) realizaram estudo em que colheram urina de jato médio de 1.370 pacientes. Obtiveram positividade de $25,62 \%$, sendo que a $G$. vaginalis foi isolada em $17,63 \%$ dos cultivos positivos. Avaliando a contagem de colônias, em $55,22 \%$ dos casos a bactéria apresentava contagem superior a $100.000 \mathrm{UFC} / \mathrm{ml}, 32,83 \%$ com contagens entre 10.000 e $100.000 \mathrm{UFC} / \mathrm{ml}$ e apenas $11,95 \%$ com contagens entre 1.000 e $10.000 \mathrm{UFC} / \mathrm{ml}^{(7)}$.

Em estudo realizado no centro médico St. Paul-Ramsey, em Minnesota, foram avaliadas 12.343 uroculturas de mulheres. Em 2.204 amostras, os resultados quantitativos indicaram provável ITU. Observou-se que 115 (5,2\%) apresentaram crescimento presuntivo de $G$. vaginalis ${ }^{(28)}$.

Josephson et al. ${ }^{(9)}$ estudaram 14.178 amostras de urina de homens e mulheres. Encontraram crescimento da $G$. vaginalis com contagem igual ou superior a $10.000 \mathrm{UFC} / \mathrm{ml}$ em 322 (2,3\%), sendo que em 72 pacientes a bactéria foi isolada em monocultivo. Entre essas amostras, cinco foram consideradas contaminantes, 43 pacientes apresentavam sintomatologia clássica de ITU, 14 eram assintomáticos e 10 apresentavam sintomas, porém não compatíveis com ITU(9).

Gónzalez-Pedraza et al. ${ }^{(8)}$ investigaram a etiologia das ITUs em 1.507 uroculturas colhidas por jato médio de pacientes com diagnóstico clínico de ITU. Consideraram como critério de positividade contagem de colônias superior a 
100.000 UFC/ml, encontrando entre os cultivos positivos $25,7 \%$ de $G$. vaginalis, sendo o segundo patógeno mais frequente no estudo( ${ }^{(8)}$.

Fairley e Birch utilizaram 190 amostras de urinas suprapúbicas para avaliar a presença de $G$. vaginalis. Os pacientes apresentavam sintomatologia de ITU. Em 33\% das urinas foi isolada a $G$. vaginalis em contagens superiores a $1.000 \mathrm{UFC} / \mathrm{ml}$, que, por se tratar de coleta suprapúbica, é um número clinicamente significativo(6)

\section{Interpretação}

A interpretação utilizada para testes rotineiros consiste em: isolamentos de uma única espécie com crescimento bacteriano superior a $100.000 \mathrm{UFC} / \mathrm{ml}$ indicam infecção; inferior a $10.000 \mathrm{UFC} / \mathrm{ml}$ sugerem contaminação vaginal ou uretral; entre 10.000 e $100.000 \mathrm{UFC} / \mathrm{ml}$ são duvidosas, tornandose necessária avaliação com base na informação médica. A maioria dos casos de pielonefrite e cistite pode ser avaliada corretamente usando esses parâmetros. Tais diretrizes, porém, falham em alguns pacientes sintomáticos, considerando que alguns casos com contagens de $100 \mathrm{UFC} / \mathrm{ml}$ podem ser clinicamente relevantes.

Deve-se ter especial atenção às amostras de crianças, em que a coleta pode ser mais difícil e infecções podem se manifestar em contagens mais baixas ( 1.000 a $10.000 \mathrm{UFC} / \mathrm{ml}$ ). Infecções são encontradas mais frequentemente em indivíduos com anormalidades anatômicas e em crianças prematuras. É necessário estar atento também a pacientes com bexiga neurogênica e idosos que recebam cuidados domiciliares de enfermagem. Para tais indivíduos, testes de triagem não são precisos e a prevalência de bacteriúria é alta nos assintomáticos (30\%) e sintomáticos (60\%). Assim, recomenda-se semear a urina com alça calibrada de 0,001 ml e 0,01 ml, em sangue de carneiro a 5\%, ágar MacConkey e ágar Chocolate (se necessário), incubando a placa no mínimo por 48 horas, devendo-se considerar o crescimento de um ou mais organismos com densidade de 100 a $10.000 \mathrm{UFC} / \mathrm{ml}^{(4)}$.

A importância clínica da presença da $G$. vaginalis isolada em amostras de urina de jato médio é de difícil avaliação, pois sua presença pode indicar contaminação vaginal. Considerando a alta taxa de colonização vaginal por essa bactéria na comunidade e a presença de sintomas de infecção urinária associada ao isolamento da bactéria nas uroculturas, podemos presumir que o micro-organismo é um patógeno urinário não convencional, porém relativamente frequente ${ }^{(7)}$. O uso de meios seletivos e a incubação por 48-72 horas em atmosfera de $\mathrm{CO}_{2}$ são fundamentais para o isolamento da bactéria.

\section{Tratamento}

Não há necessidade de realizar o teste de suscetibilidade aos antibióticos quando temos um isolado de $G$. vaginalis. Atualmente não existem pontos de corte, segundo os principais protocolos internacionais, para interpretação do antibiograma.

A bactéria apresenta um perfil de suscetibilidade bastante característico, mostrando sensibilidade a penicilina, ampicilina, eritromicina, clindamicina, trimetoprim e vancomicina. Ciprofloxacino e imipenem mostram atividade variável. A maioria dos isolados demonstra resistência a tetraciclina e minociclina. São resistentes a amicacina, aztreonam e sulfametoxazol(25).

A droga de escolha para o tratamento de vaginose bacteriana causada pela $G$. vaginalis é o metronidazol(13). O uso justifica-se, pois, além de apresentar eficácia contra a $G$. vaginalis, também age contra as bactérias anaeróbias que geralmente estão associadas. Pedraza-Avilés et al. compararam pacientes com ITU por G. vaginalis tratados com ampicilina e metronidazol. Obteve-se índice de cura de $92 \%$ para o metronidazol e $90 \%$ para a ampicilina, com $p=0,12$. A ampicilina mostrou-se mais segura e mais bem tolerada que o metronidazol(18).

\section{Conclusão}

Muitos dos urocultivos sem desenvolvimento bacteriano e cujos pacientes apresentam sintomatologia compatível com ITU podem conter patógenos infrequentes. É fundamental ao laboratório de microbiologia clínica investigar tais amostras, solicitando nova coleta quando necessário e procedendo com a semeadura e a incubação de maneira adequada, a fim de recuperar bactérias nutricionalmente exigentes, como a $G$. vaginalis.

A bactéria, descrita apenas como uma das principais causadoras da vaginose bacteriana, pode também ser responsável por ITUs e sua presença em uroculturas não deve ser desprezada.

O exame de Gram, de fácil execução e baixo custo, é um aliado essencial para a triagem das amostras, facilitando ao microbiologista não só a interpretação dos resultados, mas também o direcionamento a ser dado à amostra de urina. 


\section{Referências}

1. AGARWAL, M.; DIXON, R. A. A study to detect Gardnerella vaginalis in interstitial cystitis. British Journal of Urology, v. 88, n. 9, p. 868-70, 2001.

2. AlBiNI, C. A.; SOUZA, H. A. P.; STINGHEN, A. E. M. Coloração de Gram: como fazer, interpretar e padronizar. 2. ed. Curitiba, PR: Microscience, 2003.

3. CATLIN, B. W. Gardnerella vaginalis: characteristics, clinical considerations, and controversies. Clinical Microbiological Reviews, v. 5, n. 3, p. 213-37, 1992.

4. CLARRIDGE, J. E.; JONHSON, J. R.; PEZZLO, M. T. Cumitech 2B: laboratory diagnosis in urinary tract infections. American Society for Microbiology, Washington, D.C., 1998.

5. CRUZ, J. F. J.; BROSETA, E.; GOBERNADO, M. Infección urinária. Actas Urológicas Españolas, v. 26, n. 8, p. 563-73, 2002.

6. FAIRLEY, K. F.; BIRCH, D. F. Unconventional bacteria in urinary tract disease: Gardnerella vaginalis. Kidney International, v. 23, n. 6, p. 862-5, 1983.

7. GINESTRE-PERÉZ, M. et al. Gardnerella vaginalis y uropatógenos convencionales en pacientes ambulatorios. Revista de la Sociedad Venezolana de Microbiologia, v. 21, n. 2, 2001.

8. GONZÁLEZ-PEDRAZA, A. et al. Papel de las bacterias asociadas a infecciones de transmisión sexual en la etiología de la infección de vías urinarias bajas en el primer nivel de atención médica. Enfermedades Infecciosas \& Microbiologia Clínica, v. 21, n. 2, p. 89-92, 2003.

9. JOSEPHSON, S. et al. Gardnerella vaginalis in the urinary tract: incidence and significance in a hospital population. Obstetrics \& Ginecology, v. 71, n. 2, p. 245-50, 1988.

10. KINGHORN, G. R. et al. Balanoposthitis associated with Gardnerella vaginalis infection in men. Brazilian Journal of Veneral Diseases, v. 58, p. 127-9, 1982.

11. LAM, M. H.; BIRCH, D. F. Survival of Gardnerella vaginalis in human urine. American Journal of Clinical Pathology, v. 95. n. 2, p. 234-9, 1991.

12. LAM, M. H.; BIRCH, D. F.; FAIRLEY, K. F. Prevalence of Gardnerella vaginalis in the urinary tract. Journal of Clinical Microbiology, v. 26, n. 6, p. 1130-3, 1988.

13. MANDELL, G. L.; BENNET, J. E.; DOLIN, R. Principles and practices of infectious diseases. Philadelphia: Elsevier, 2005.

14. MCCARTER, Y. S. et al. Cumitech 2C: laboratory diagnosis of urinary tract infections. American Society for Microbiology, Washington, D.C., 2009.
15. MCDOWALL, D. R. M. et al. Anaerobic and other fastidious microorganisms in asymptomatic bacteriuria in pregnant women. Journal of Infectious Diseases, v. 144, p. 114-22, 1981.

16. OPLUSTIL, C. P. et al. Procedimentos básicos em microbiologia clínica. 2. ed. São Paulo: Sarvier, 2004.

17. PAPAPETROPOULOU, M.; PAPPAS, A. The acute urethral syndrome in routine practice. Journal of Infectology, v. 14, p. 113-8, 1987.

18. PEDRAZA-AVILÉS, A. G. et al. Treatment of urinary tract infection by Gardnerella vaginalis: a comparison of oral metronidazole versus ampicillin. Revista Latinoamericana de Microbiologia, v. 43, n. 2, p. 65-9, 2001.

19. RODRIGUEZ, A. et al. Cistitis por Gardnerella vaginalis. Reporte de caso y revisión. Revista de la Facultad de Medicina, v. 23, n. 2, p. 98-101, 2000.

20. ROTTINI, G. et al. Identification and partial characterization of a cytolytic toxin produced by Gardnerella vaginalis. Infection and Immunity, v. 58, n. 11, p. 3751-8, 1990.

21. SAVIGE, J. A.; BIRCH, D. F.; FAIRLEY, D. F. Comparison of mid catheter collection and suprapubic aspiration of urine for diagnosing bacteriuria due to fastidious micro-organisms. The Journal of Urology, v. 129, n. 1, p. 62-3, 1983.

22. SILVA, C. H. P. M.; NEUFELD, P. M. Bacteriologia e micologia. Rio de Janeiro: Revinter, 2006.

23. SMITH, S. M.; OGBARA, T.; ENG, R. H. Involvement of Gardnerella vaginalis in urinary tract infections in men. Journal of Clinical Microbiology, v. 30, n. 6, p. 1575-7, 1992.

24. STURM, A. W. Gardnerella vaginalis in infections of the urinary tract. Journal of Infection, v. 18, p. 45-9, 1989.

25. SUGARMAN, I. D. et al. Bacteriological state of the urine in symptom-free adult males. British Journal of Urology, v. 66, n. 2, p. 148-51, 1990.

26. WATSON, R. A. Gardnerella vaginalis: genitourinary pathogen in men. Urology, v. 25, n. 3, p. 217-22, 1985.

27. WINN, W. J. et al. Koneman's color atlas and textbook of diagnostic microbiology. Philadelphia: Lippincott Williams \& Wilkins, 2006.

28. WOOLFREY, B. F.; IRELAND, G. K.; LALLY, R. T. Significance of Gardnerella vaginalis in urine cultures. American Journal of Clinical Pathology, v. 86. n. 3, p. 324-9, 1986. 